\title{
Crystal structures of salts and cocrystal of 1,3,5-triazine derivatives with thiophene carboxylic acid derivatives: an investigation on supramolecular interactions
}

\author{
O. K. Prajina' ${ }^{10} \cdot$ P. T. Muthiah ${ }^{1} \cdot$ F. Perdih ${ }^{2}$
}

C Springer Nature Switzerland AG 2019

\begin{abstract}
Present work gives an account of different types of non covalent interactions encountered in the supramolecular architectures of new salts and cocrystal formed between derivatives of 1,3,5-triazine and thiophene carboxylic acid. The novel salts formed between derivatives of thiophene carboxylic acid and 1,3,5-triazine are 2, 4-diamino-6-methyl-1,3,5-triazin-1-ium 5-carboxythiophene-2-carboxylate monohydrate, $\mathrm{C}_{4} \mathrm{H}_{8} \mathrm{~N}_{5}{ }^{+} \cdot \mathrm{C}_{6} \mathrm{H}_{3} \mathrm{O}_{4} \mathrm{~S}_{1}^{-} \cdot \mathrm{H}_{2} \mathrm{O}$ (I) and 2,4-diamino-6-methyl-1,3,5-triazin1-ium 3-bromothiophene-2-carboxylate monohydrate, $\mathrm{C}_{4} \mathrm{H}_{8} \mathrm{~N}_{5}^{+} \cdot \mathrm{C}_{5} \mathrm{H}_{2} \mathrm{O}_{2} \mathrm{~S}_{1} \mathrm{Br}_{1}^{-} \cdot \mathrm{H}_{2} \mathrm{O}$ (II). The new cocrystal is a 1:1 cocrystal formed between 2,4-diamine-6-phenyl-1,3,5-triazine and 2,5-dichlorothiophene-3-carboxylic acid, $\mathrm{C}_{9} \mathrm{H}_{9} \mathrm{~N}_{5} \cdot \mathrm{C}_{5} \mathrm{H}_{2} \mathrm{O}_{2} \mathrm{~S}_{1} \mathrm{Cl}_{2}$ (III). The newly synthesized salts (I and II) and cocrystal (III) have been characterized by single-crystal X-ray diffraction. Supramolecular heterosynthons, homosynthons observed via $\mathrm{N}-\mathrm{H} \cdots \mathrm{O}, \mathrm{N}-\mathrm{H} \cdots \mathrm{N}$ and $\mathrm{O}-\mathrm{H} \cdots \mathrm{N}$ hydrogen bonds are also discussed. Anion $\cdots \pi$ interaction between carboxylate oxygen and aromatic rings of thiophene and triazine are observed in salt (I). $\pi \cdots \pi$ interaction is present between thiophene and triazine rings in salt (II). $\mathrm{R}_{2}^{2}(8)$ ring motif is formed in cocrystal (III) via $\mathrm{N}-\mathrm{H} \cdots \mathrm{O}$ and $\mathrm{O}-\mathrm{H} \cdots \mathrm{N}$ hydrogen bonds. Further stabilisation of cocrystal (III) via $\mathrm{Cl} \cdots \mathrm{O}, \mathrm{Cl} \cdots \mathrm{Cl}$ interactions as well as $\pi \cdots \pi$ interactions (triazine $\cdots$ triazine rings and triazine...phenyl rings) are also investigated.
\end{abstract}

Keywords Supramolecular interactions $\cdot$ Ring motif $\cdot$ Heterosynthon $\cdot$ Homosynthon

\section{Introduction}

Supramolecular chemistry deals with studies on noncovalent interactions and molecular assemblies. This knowledge acts as a basic tool for design of new multicomponent crystalline materials or supramolecular materials. These supramolecular materials show various applications in catalysis [1, 2], magnetism [3, 4], photoluminescence $[5,6]$, drug delivery and design $[7,8]$, gas storage $[9,10]$. Among the various non-covalent interactions, hydrogen bonding interactions like $\mathrm{O}-\mathrm{H} \cdots \mathrm{O}$, $\mathrm{N}-\mathrm{H} \cdots \mathrm{O}, \mathrm{N}-\mathrm{H} \cdots \mathrm{N}$ and $\mathrm{C}-\mathrm{H} \cdots \mathrm{O}$ have received considerable attention as they play important role in molecular recognition [11]. Anion $\cdots \pi$ interactions, cation $\cdots \pi$ interactions and $\pi \cdots \pi$ interactions are the commonly occurring non-covalent interactions leading to generate unique supramolecular network from simple building blocks [12]. In addition to these interactions, halogen substituted carboxylic acid derivatives perform a significant role in altering the supramolecular architectures via various halogen $(X)$ involving interactions like $X \cdots X, X \cdots O$, $X \cdots \pi$ interactions etc. [13]. Halogen bonding is a strong tool for constructing supramolecular networks due to its strength and directionality. Halogen bonds have recently been widely applied in supramolecular chemistry as an alternative to hydrogen bonds to control solid-state structures. There are studies which have investigated the competition between hydrogen bond and halogen bond in cocrystals [14]. Here we selected halogen substituted thiophene carboxylic acids to investigate halogen

O. K. Prajina, prajina89@gmail.com | ${ }^{1}$ School of Chemistry, Bharathidasan University, Tiruchirappalli, Tamilnadu 620024, India. ${ }^{2}$ Faculty of Chemistry and Chemical Technology, University of Ljubljana, Večna, pot, 113, PO Box 537, 1000 Ljubljana, Slovenia. 
involving interactions due to the halogen substitution. Impact of halogen bonds in crystal engineering has been widely studied in halogenated aromatic compounds [14].

Aminotriazines are selected for the study as they have proven their great potential in crystal engineering as they contain large number of coordination/hydrogen bonding sites, for their $\pi$-interaction abilities [12]. Investigation on various supramolecular motifs and molecular self assemblies among aminotriazine derivatives were always interest of research. A series of 1, 3, 5-triazine based compounds are found to have activity against protozoan parasites which causes a number of diseases to human [15]. Studies are going on to investigate the structure-activity relationship by altering the substituents of 1,3,5-triazine derivatives [15]. Antimicrobial activities were evaluated for 1,3,5-triazine derivatives against various bacteria [16]. Studies of 1,3,5-triazine derivatives showed that length of alkyl substitution and presence of nitrogen atom in triazine has significant effects on anticancer activity [17]. Apart from biological activities, triazine derivatives have eminent capacity as light stabilizers for polymers [18].

\section{Experimental}

\subsection{Synthesis and crystallization}

Compounds (I)-(III) were prepared by mixing hot methanol-water $(1: 1 \mathrm{v} / \mathrm{v})$ solutions (total volume $0.03 \mathrm{~L}$ ) of 2,4-diamino-6-methyl-1,3,5-triazine with thiophene dicarboxylic acid [for I], 2,4-diamino-6-methyl-1,3,5-triazine with 3-bromothiophene-2-carboxylate [for II] and 2,4-diamine-6-phenyl-1,3,5-triazine with 2,5-dichlorothiophene-3-carboxylic acid [for III]. The solutions were warmed to $343 \mathrm{~K}$ over a water bath for 30 minutes and then cooled slowly to $298 \mathrm{~K}$ after filtration. Colourless crystals were collected from the respective mother liquor solutions after 7 days. Chemical Structures of novel salts and cocrystal are presented in Scheme 1.

\subsection{Measurements (single crystal x-ray diffraction)}

Intensity data sets were collected at $293 \mathrm{~K}$ for on a SuperNova dual with an Atlas diffractometer. Data reduction was done by CrysAlis PRO [19]. The structures were solved

Scheme 1 Chemical structures of I-III

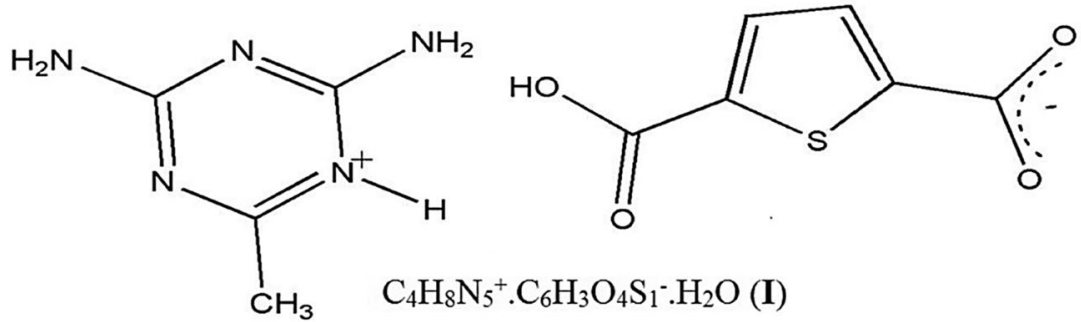

. $\mathrm{H} 2 \mathrm{O}$<smiles></smiles><smiles>O=C(O)c1sccc1Br</smiles>

. $\mathrm{H} 2 \mathrm{O}$

$\mathrm{C}_{4} \mathrm{H}_{8} \mathrm{~N}_{5}{ }^{+} \cdot \mathrm{C}_{5} \mathrm{H}_{2} \mathrm{O}_{2} \mathrm{~S}_{1} \mathrm{Br}_{1}^{-} \cdot \mathrm{H}_{2} \mathrm{O}$ (II)<smiles>O=C(O)c1cc(Cl)sc1Cl</smiles><smiles>N=C(N)N=C(N)N</smiles>

$\mathrm{C}_{9} \mathrm{H}_{9} \mathrm{~N}_{5} \cdot \mathrm{C}_{5} \mathrm{H}_{2} \mathrm{O}_{2} \mathrm{~S}_{1} \mathrm{Cl}_{2}$ (III) 
SUPERFLIP [20] and subsequent Fourier analyses, refined anisotropically by full-matrix least-squares method using SHELXL2014 [21] within the WINGX suite of software, based on $\mathrm{F}^{2}$ with all reflections. The molecular structures were drawn using the PLATON [22] and Mercury [23]. The crystals remained stable throughout the data collection.

Crystal data and structure refinement details are summarized in Table 1. All the hydrogen atoms were initially located in difference Fourier maps and were subsequently treated as riding atoms in geometrically idealized positions, with $\mathrm{C}-\mathrm{H}=0.93$ (aromatic) or $0.96 \AA$ (methyl), $\mathrm{N}-\mathrm{H}=0.86 \AA$ and $\mathrm{O}-\mathrm{H}=0.82 \AA$ (hydroxyl), whereas hydrogen atom coordinates in water molecules were refined by constraining the $\mathrm{O}-\mathrm{H}$ bond length (I, II). All $\mathrm{H}$ atoms were refined with $U_{i s o}(\mathrm{H})=k U_{e q}(\mathrm{C}, \mathrm{N}, \mathrm{O})$, where $k=1.5$ for hydroxy, water and methyl $\mathrm{H}$ atoms and 1.2 for all other $\mathrm{H}$ atoms.

\section{Results and discussions}

\subsection{Structural commentary}

The salt (I) crystallizes in triclinic system with space group $P$-1. The asymmetric unit of salt (I) consists of one 2 , 4-diamino-6-methyl-1,3,5-triazin-1-ium (DAMT) cation, one 5-carboxythiophene-2-carboxylate (CTC) anion and a water molecule (Fig. 1). The triazinium cation is protonated at the $\mathrm{N} 1$ position. It is confirmed by increase in internal bond angle. Internal angle at unprotonated N3 (C2-N3-C4) is $115.7(2)^{\circ}$ and at N5 (C4-N5-C6) is 115.4 (7) $)^{\circ}$, while internal angle at protonated $\mathrm{N} 1(\mathrm{C} 6-\mathrm{N} 1-\mathrm{C} 2)$ is $119.2(2)^{\circ}$. There is not much discrepancy between the external bond angles at the carbon (C8) of carboxylate ion $\left(\mathrm{C} 9-\mathrm{C} 8-\mathrm{O} 2=120.77(17)^{\circ}\right.$ and $\left.\mathrm{C} 9-\mathrm{C} 8-01=113.87(15)^{\circ}\right)$.

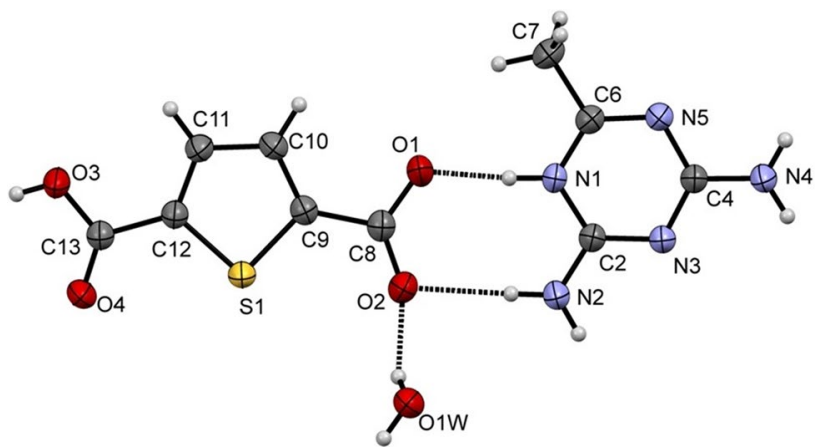

Fig. 1 ORTEP view of (I) with the atom-numbering scheme. Displacement ellipsoids are drawn at $50 \%$ probability level. Dashed lines represent hydrogen bonds

\begin{tabular}{|c|c|c|c|}
\hline Crystal data & (I) & (II) & (III) \\
\hline Empirical formula & $\mathrm{C} 10 \mathrm{H} 13 \mathrm{~N} 5 \mathrm{O} 5 \mathrm{~S}$ & $\mathrm{C} 9 \mathrm{H} 12 \mathrm{Br} 55 \mathrm{O} 3 \mathrm{~S}$ & $\mathrm{C} 14 \mathrm{H} 11 \mathrm{Cl} 2 \mathrm{~N} 5 \mathrm{O} 2 \mathrm{~S}$ \\
\hline Formula weight & 315.31 & $690.46(12)$ & 384.24 \\
\hline Temperature (K) & 293 & 293 & 293 \\
\hline$\lambda(\AA)$ & 0.71073 & 1.54184 & 1.54184 \\
\hline Crystal system & $P-1$ & $P-1$ & $P-1$ \\
\hline Space group & Triclinic & Triclinic & Triclinic \\
\hline a $(\AA)$ & $8.3921(6)$ & $8.0095(8)$ & $7.1038(12)$ \\
\hline $\mathrm{b}(\AA)$ & $9.6250(8)$ & $9.2549(9)$ & $7.9449(11)$ \\
\hline$c(\AA)$ & $10.2803(9)$ & $9.9864(10)$ & $15.4870(14)$ \\
\hline$a\left(^{\circ}\right)$ & $62.339(9)$ & $78.831(8)$ & $86.934(9)$ \\
\hline$\beta\left(^{\circ}\right)$ & $74.447(7)$ & $75.860(8)$ & $81.930(11)$ \\
\hline$\gamma\left({ }^{\circ}\right)$ & $66.819(8)$ & $76.434(8)$ & $65.759(15)$ \\
\hline$V\left(\AA^{3}\right)$ & $672.37(11)$ & $690.46(12)$ & $789.1(2)$ \\
\hline Z & 2 & 2 & 2 \\
\hline$\rho$ calcd $\left(\mathrm{g} / \mathrm{cm}^{3}\right)$ & 1.558 & 1.684 & 1.617 \\
\hline$\mu\left(\mathrm{mm}^{-1}\right)$ & 0.272 & 5.609 & 5.117 \\
\hline$F(000)$ & 328.0 & 352.0 & 392.0 \\
\hline Crystal size (mm) & $0.05 \times 0.20 \times 0.40$ & $0.10 \times 0.25 \times 0.30$ & $0.30 \times 0.30 \times 0.10$ \\
\hline No of reflections collected & 3084 & 2624 & 2991 \\
\hline Goodness-of-fit on $\mathrm{F}^{2}$ & 1.036 & 1.035 & 1.000 \\
\hline Final R1 index $[I>2 \sigma(I)]$ & 0.0469 & 0.0509 & 0.0361 \\
\hline$w^{2} R_{2}$ (all data) & 0.1334 & 0.1580 & 0.1037 \\
\hline $\begin{array}{l}\text { Largest difference in peak and } \\
\text { hole }\left(\mathrm{e} \AA^{-3}\right)\end{array}$ & $0.442,-0.286$ & $0.998,-0.654$ & $0.293,-0.349$ \\
\hline
\end{tabular}


C8-O1 and C8-O2 distances are similar [1.272(3) ̊ and $1.238(2) \AA$, respectively]. The two external bond angles at the carbon C13 of the carboxyl group are $124.0(2)^{\circ}$ and $112.5(2)^{\circ}$. The high discrepancy between these two angles is typical of a unionized carboxyl group, and the $\mathrm{C}=\mathrm{O}$ distance is 1.216 (3) $\AA$ and C-OH distance of 1.314 (3) $\AA$ [14]. These parameters indicate that carboxylic group of one arm (with (8) of thiophene is in deprotonated form and the other arm (with C13) is in neutral form.

Salt (II) crystallizes in the triclinic system with space group $P-1$. The asymmetric unit of salt (II) consists of a 2, 4-diamino-6-methyl-1,3,5-triazin-1-ium cation, 3-bromothiophene-2-carboxylate anion and a water molecule (Fig. 2). Internal angle at unprotonated N3 (C2-N3-C4) is $115.7(2)^{\circ}$ and at N5 (C4-N5-C6) is $115.8(2)^{\circ}$, while internal angle at protonated $\mathrm{N} 1(\mathrm{C} 6-\mathrm{N} 1-\mathrm{C} 2)$ is $119.2(2)^{\circ}$. There is not much discrepancy between the external bond angles at the carbon of carboxylate ion $\left(\mathrm{C} 9-\mathrm{C} 8-\mathrm{O} 2=119.4(4)^{\circ}\right.$ and $\left.\mathrm{C} 9-\mathrm{C} 8-\mathrm{O} 1=115.5(3)^{\circ}\right)$. C8-O1 and $\mathrm{C} 8-\mathrm{O} 2$ distances are similar [1.266 (5) $\AA$ and 1.240 (5) $\AA$, respectively].

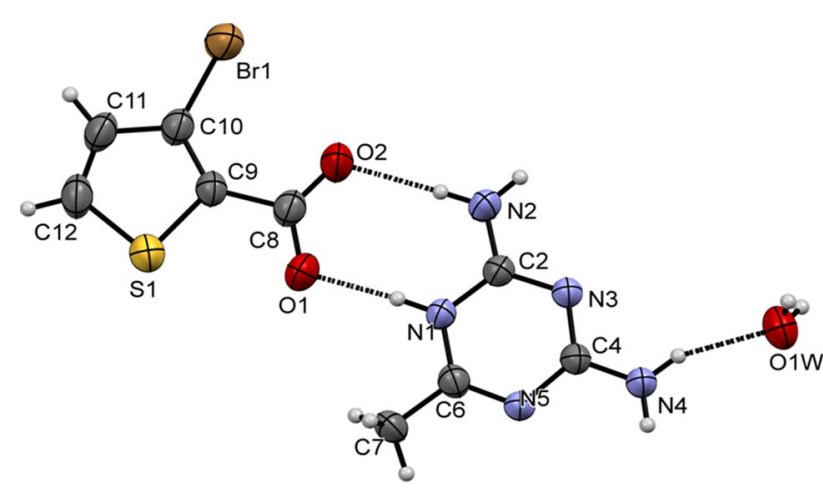

Fig. 2 ORTEP view of (II) with the atom-numbering scheme. Displacement ellipsoids are drawn at 50\% probability level. Dashed lines represent hydrogen bonds
Cocrystal (III) crystallizes in the triclinic system with space group $P-1$. The asymmetric unit of the cocrystal (III) consists of one molecule of 2,4-diamine-6-phenyl-1,3,5triazine (DAPT) and 2,5-dichlorothiophene-3-carboxylic acid (DCTPC) (Fig. 3). Internal angle at unprotonated N3 (C2-N3-C4) is $115.54(15)^{\circ}$, at N5 (C4-N5-C6) is 114.80 $(15)^{\circ}$, and at N1 (C6-N1-C2) is $114.50(16)^{\circ}$. The two external bond angles at the carbon of the carboxyl group are $121.3(2)^{\circ}$ and $114.5(1)^{\circ}$. The high discrepancy between these two angles is typical for unionized carboxyl group, and the $\mathrm{C}=\mathrm{O}$ distance is 1.213 (3) $\AA$ and $\mathrm{C}-\mathrm{OH}$ distance of 1.299 (3) $\AA$. The bond parameters of the thiophene rings (I-III) agree with those in structures reported earlier [24].

\subsection{Supramolecular features of (I), (II) and (III)}

Among the three crystals, two are salts (I and II) and one is cocrystal (III) of thiophene carboxylic acid derivatives and substituted 1,3,5-triazine.

In salt (I), a robust $R_{2}^{2}(8)$ ring motif (supramolecular heterosynthon) is formed via $\mathrm{N}-\mathrm{H}$... O hydrogen bond interactions between DAMT ions (atoms N1 and N2) and CTC ions (atoms $\mathrm{O} 1$ and O2) [25]. Oxygen atom (O2) acts as bifurcated acceptor via $\mathrm{N} 2-\mathrm{H} 2 \mathrm{~A} \cdots \mathrm{O} 2$ and $\mathrm{O} 1 \mathrm{~W}-\mathrm{H} 2 \mathrm{~W} \cdots \mathrm{O} 2$ hydrogen bonding. The symmetry related molecules of DAMT interact through a pair of $\mathrm{N}-\mathrm{H}$... N hydrogen bonds to form a discrete bimolecular homosynthon. Oxygen (O4) atom is involved in N4-H4B ... $4^{\text {iv }}$ and $\mathrm{N} 2-\mathrm{H} 2 \mathrm{~B} \cdots \mathrm{O} 4^{\mathrm{ii}}$ hydrogen bonding [symmetry code (iv) $x-1, y+1, z+1$, (ii) $-\mathrm{x}+2,-\mathrm{y},-\mathrm{z}+1] . \mathrm{N}-\mathrm{H} \ldots \mathrm{O}$ and $\mathrm{N}-\mathrm{H}$... N hydrogen bonds between two DAMT and CTC ions leads to a ring motif with $\mathrm{R}_{3}^{2}(8)$ graph-set. Hydrogen bond parameters of (I) are listed in Table 2. Similarly, $\mathrm{O}-\mathrm{H} \cdots \mathrm{O}, \mathrm{O}-\mathrm{H} \cdots \mathrm{N}$ and $\mathrm{N}-\mathrm{H} \cdots \mathrm{O}$ hydrogen bonds between DAMT, water and CTC lead to a ring motif with $R_{3}^{3}(10)$ graph-set. In this salt, supramolecular ribbon containing $R_{3}^{2}(8), R_{2}^{2}(8)$ and $R_{3}^{3}(10)$ ring motifs generating a quadruple DADA $(\mathrm{D}=$ hydrogen-bond donor
Fig. 3 ORTEP view of (III) with the atom-numbering scheme. Displacement ellipsoids are drawn at 50\% probability level. Dashed lines represent hydrogen bonds

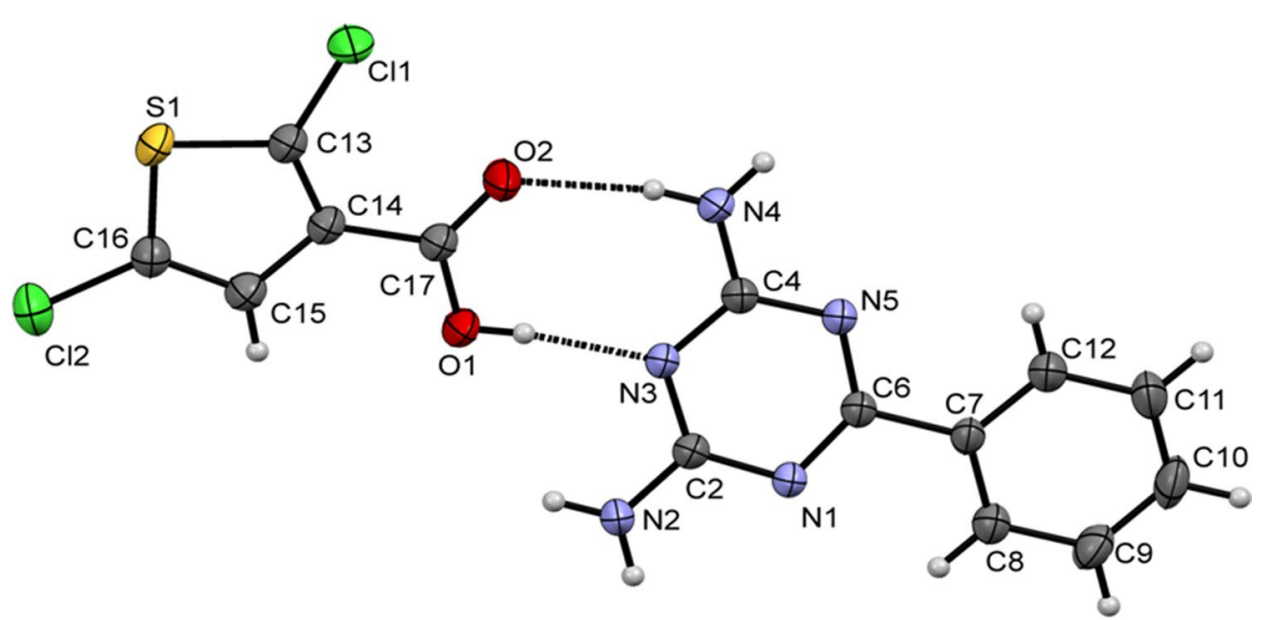


Table 2 Hydrogen-bond geometry $\left(\AA^{\circ},{ }^{\circ}\right)$ for (I)

\begin{tabular}{|c|c|c|c|c|}
\hline$D-\mathrm{H} \cdots A$ & $D-\mathrm{H}$ & $\mathrm{H} \cdots A$ & $D \cdots A$ & $D-\mathrm{H} \cdots A$ \\
\hline 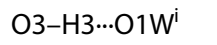 & 0.82 & 1.77 & $2.551(2)$ & 159.1 \\
\hline $\mathrm{N} 1-\mathrm{H} 1 \ldots \mathrm{O} 1$ & 0.86 & 1.70 & $2.556(2)$ & 173.7 \\
\hline $\mathrm{N} 2-\mathrm{H} 2 \mathrm{~B} \cdots \mathrm{O} 4^{\mathrm{ii}}$ & 0.86 & 2.24 & $3.092(2)$ & 170.7 \\
\hline $\mathrm{N} 2-\mathrm{H} 2 \mathrm{~A} \cdots \mathrm{O} 2$ & 0.86 & 2.05 & $2.907(2)$ & 171.4 \\
\hline $\mathrm{N} 4-\mathrm{H} 4 \mathrm{~A} \cdots \mathrm{N} 3^{\mathrm{iii}}$ & 0.86 & 2.12 & $2.959(2)$ & 166.7 \\
\hline $\mathrm{N} 4-\mathrm{H} 4 \mathrm{~B} \cdots \mathrm{O} 4^{\mathrm{iv}}$ & 0.86 & 2.19 & $2.8894(19)$ & 138.9 \\
\hline $\mathrm{O} 1 \mathrm{~W}-\mathrm{H} 1 \mathrm{~W} \cdots \mathrm{N} 5^{\mathrm{v}}$ & $0.820(10)$ & $1.988(11)$ & $2.802(2)$ & $172(3)$ \\
\hline $\mathrm{O} 1 \mathrm{~W}-\mathrm{H} 2 \mathrm{~W} \cdots \mathrm{O} 2$ & $0.815(10)$ & $2.096(16)$ & $2.868(2)$ & $158(3)$ \\
\hline
\end{tabular}

Symmetry codes: (i) $x, y, z-1$; (ii) $-x+2,-y,-z+1$; (iii) $-x+1,-y+1$, $-z+2$; (iv) $x-1, y+1, z+1$; (v) $x+1, y-1, z$

and $A=$ hydrogen bond acceptor) array of hydrogen bonds is observed. This supramolecular ribbon is connected by water molecule via $\mathrm{O} 1 \mathrm{~W}-\mathrm{H} 1 \mathrm{~W}$-...O2 hydrogen bonding to form large ring motif, $R_{6}^{7}(33)$, which leads to the formation of supramolecular sheet (Fig. 4). The commonly occurring carboxy|...carboxylate and carboxy|...carboxyl interactions are not present in the crystal structure [26]. This may be due to the hydrogen bonds involving water and the presence of $R_{2}^{2}(8)$ heterosynthon and $R_{2}^{2}(8)$ homosynthon (base pair).
Anion $\cdots \pi$ interaction occurs whenever an anion is perpendicular to the aromatic ring at a distance less than $4.5 \AA$, in this structure carboxylate oxygen $(\mathrm{O} 1)$ interacts with nearly perpendicular aromatic ring of thiophene and that of triazine at distances of 3.180 (2) $\AA$ and 3.483 (2) $\AA$, respectively with ${ }^{<} \mathrm{C} 8-\mathrm{O} 1 \cdots \mathrm{cg} 1=91.1(1)^{\circ}$ and < $8-01 \cdots \mathrm{cg} 2=86.3(1)^{\circ}$ (Fig. 5) [27].

In salt (II), a primary $\mathrm{R}_{2}^{2}(8)$ ring motif is formed via $\mathrm{N} 1-\mathrm{H} 1 \cdots \mathrm{O} 1^{\mathrm{i}}$ and $\mathrm{N} 2-\mathrm{H} 2 \cdots \mathrm{O} 2^{\mathrm{i}}$ [symmetry code (i); $1-\mathrm{x}$, $1-y, 2-z]$ hydrogen bonding interactions between the DAMT and BTPC ions (Fig. 5). DAMT ions self assemble via $\mathrm{N}-\mathrm{H} \cdots \mathrm{N}$ hydrogen bonding with $\mathrm{R}_{2}^{2}(8)$ ring motif generating a quadruple DADA hydrogen bonding array. This forms a supramolecular chain. This supramolecular chain interacts with water and BTPC via O-H..., $\mathrm{N}-\mathrm{H} \cdots \mathrm{O}$ and $\mathrm{C}-\mathrm{H} \cdots \mathrm{O}$ hydrogen bonds with $\mathrm{R}_{3}^{2}(8)$ and $\mathrm{R}_{4}^{3}(10)$ ring motifs forming a supramolecular ribbon (Fig. 6). Hydrogen bond parameters of (II) are listed in Table 3. DAMT ions form $\mathrm{N}-\mathrm{H} \cdot \cdots \mathrm{N}$ intermolecular hydrogen bonds forming $\mathrm{R}_{2}^{2}(8)$ ring motif has been reported [28].

$\pi \cdots \pi\left(\mathrm{Cg} 1 \cdots \mathrm{Cg} 2^{\mathrm{v}}\right.$ and $\left.\mathrm{Cg} 2 \cdots \mathrm{Cg} 1^{\mathrm{vi}}\right)$ interactions with interplanar distance of $3.843(2) \AA$ and slip angle $23.2^{\circ}$ [symmetry code; $v i=1+x, y, z, v=-1+x, y, z$ ] between the triazine ring and thiophene ring are present (Fig. 7).

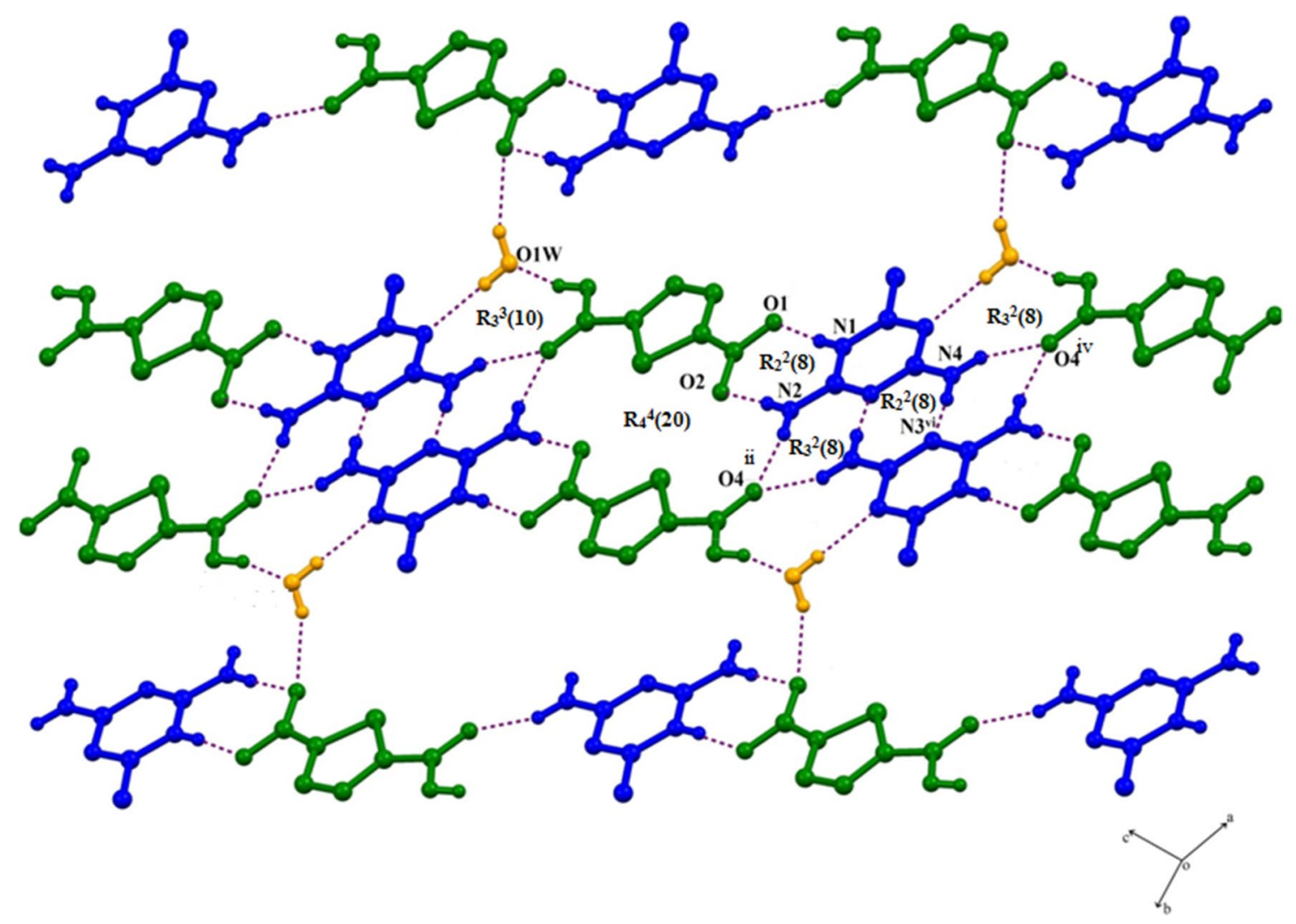

Fig. 4 Supramolecular architecture developed via $\mathrm{N}-\mathrm{H} \cdots \mathrm{O}$ and $\mathrm{O}-\mathrm{H} \cdots \mathrm{O}$ hydrogen bonds in (I) 


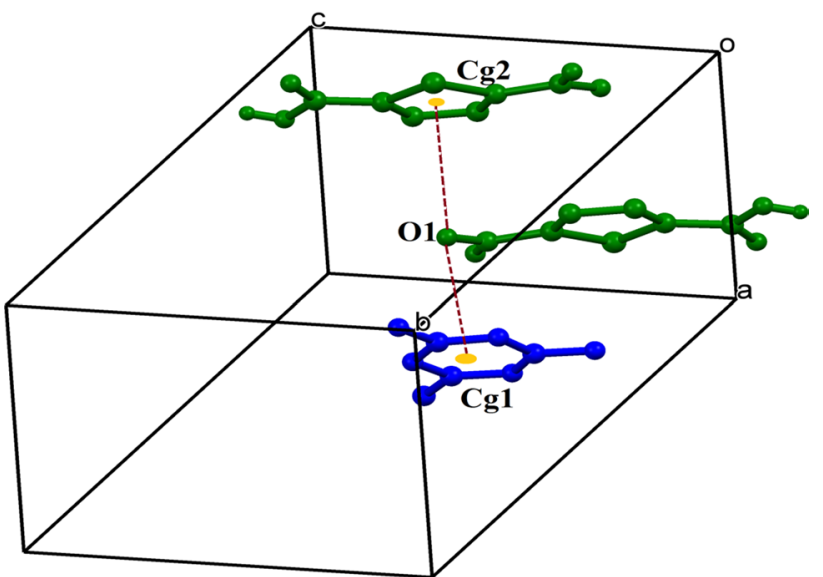

Fig. 5 Anion $\cdots \pi$ interactions present in (I)

In cocrystal (III), one molecule of 2,4-diamine-6-phenyl-1,3,5-triazine (DAPT) and one molecule of 2,5-dichloro-

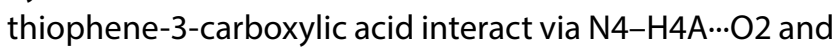
$\mathrm{O} 1-\mathrm{H} 1 \ldots \mathrm{N} 3$ hydrogen bonds to form the robust $\mathrm{R}_{2}^{2}(8)$ ring motif (supramolecular heterosynthon) (Fig. 8). Hydrogen bond parameters of (III) are listed in Table 4. Two types of base pairing are present among DAPT molecules via $\mathrm{N} 2-\mathrm{H} 2 \mathrm{~A} \cdots \mathrm{N} 1^{\mathrm{i}}$ and $\mathrm{N} 4-\mathrm{H} 4 \mathrm{~B} \cdots \mathrm{N} 5^{\mathrm{ii}}$ hydrogen bonds [symmetry code: (i) $-x+1,-y,-z+1$; (ii) $-x+2,-y+1,-z+1$ ], forming $R_{2}^{2}(8)$ ring motifs, leading to a supramolecular chain. Similar type of base pairing via $\mathrm{N}-\mathrm{H} \cdot \cdots \mathrm{N}$ hydrogen bonds leading to $R_{2}^{2}(8)$ ring motifs are observed among
Table 3 Hydrogen-bond geometry $\left(\AA{ }^{\circ}\right)$ for (II)

\begin{tabular}{lllll}
\hline$D-\mathrm{H} \cdots A$ & $D-\mathrm{H}$ & $\mathrm{H} \cdots A$ & $D \cdots A$ & $D-\mathrm{H} \cdots A$ \\
\hline $\mathrm{N} 1-\mathrm{H} 1 \cdots \mathrm{O} 1^{\mathrm{i}}$ & 0.86 & 1.83 & $2.689(4)$ & 175.1 \\
$\mathrm{~N} 2-\mathrm{H} 2 \mathrm{~B} \cdots \mathrm{N} 3^{\mathrm{ii}}$ & 0.86 & 2.24 & $3.084(4)$ & 166.8 \\
$\mathrm{~N} 2-\mathrm{H} 2 \mathrm{~A} \cdots \mathrm{O} 2^{\mathrm{i}}$ & 0.86 & 1.99 & $2.842(4)$ & 171.3 \\
$\mathrm{~N} 4-\mathrm{H} 4 \mathrm{~A} \cdots \mathrm{O} 1 \mathrm{~W}$ & 0.86 & 2.01 & $2.794(4)$ & 151.0 \\
$\mathrm{~N} 4-\mathrm{H} 4 \mathrm{~B} \cdots \mathrm{N} 5^{\mathrm{iii}}$ & 0.86 & 2.15 & $3.004(4)$ & 175.5 \\
$\mathrm{O}^{\mathrm{W}}-\mathrm{H} 1 \mathrm{~W} \cdots \mathrm{O} 1^{\mathrm{ii}}$ & $0.821(10)$ & $2.02(2)$ & $2.823(5)$ & $167(7)$ \\
$\mathrm{O}^{\mathrm{W}}-\mathrm{H} 2 \mathrm{~W} \cdots \mathrm{O} 2^{\mathrm{iv}}$ & $0.818(10)$ & $1.988(15)$ & $2.800(5)$ & $172(7)$ \\
\hline
\end{tabular}

Symmetry codes: (i) $-x+1,-y+1,-z+2$; (ii) $-x+1,-y+1,-z+1$; (iii) $-x,-y+2,-z+1 ;$ (iv) $x, y, z-1$

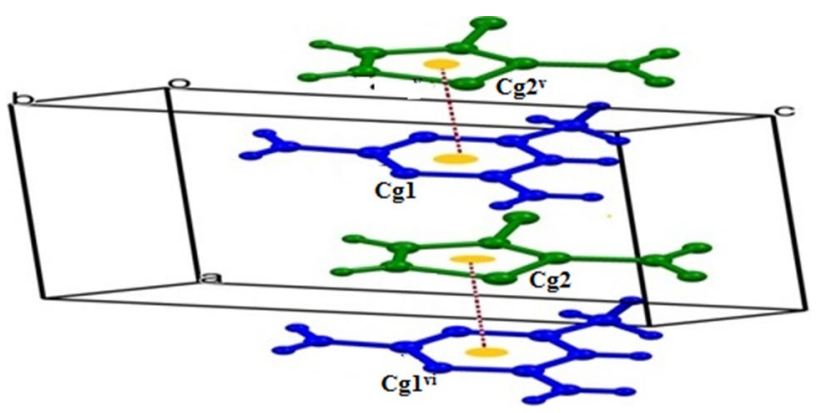

Fig. $7 \quad \pi \cdots \pi$ interactions present in (II)

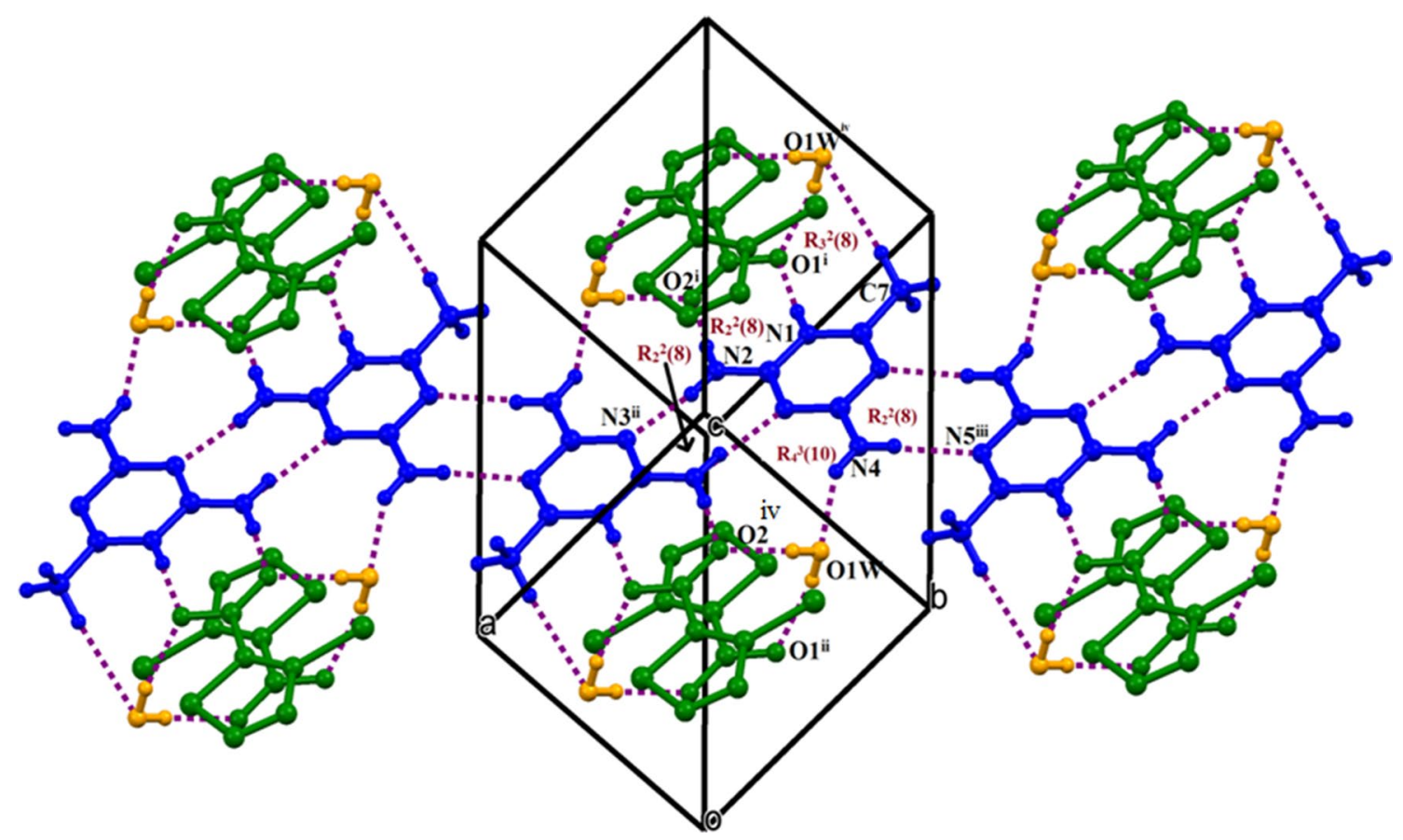

Fig. 6 Supramolecular architecture developed via $\mathrm{N}-\mathrm{H} \cdots \mathrm{O}, \mathrm{O}-\mathrm{H} \cdots \mathrm{O}$ and $\mathrm{C}-\mathrm{H} \cdots \mathrm{O}$ hydrogen bonds in (II) 
Fig. 8 Supramolecular architecture developed via $\mathrm{N}-\mathrm{H} \cdots \mathrm{O}$ and $\mathrm{N}-\mathrm{H} \cdots \mathrm{N}$ hydrogen bonds in (III)

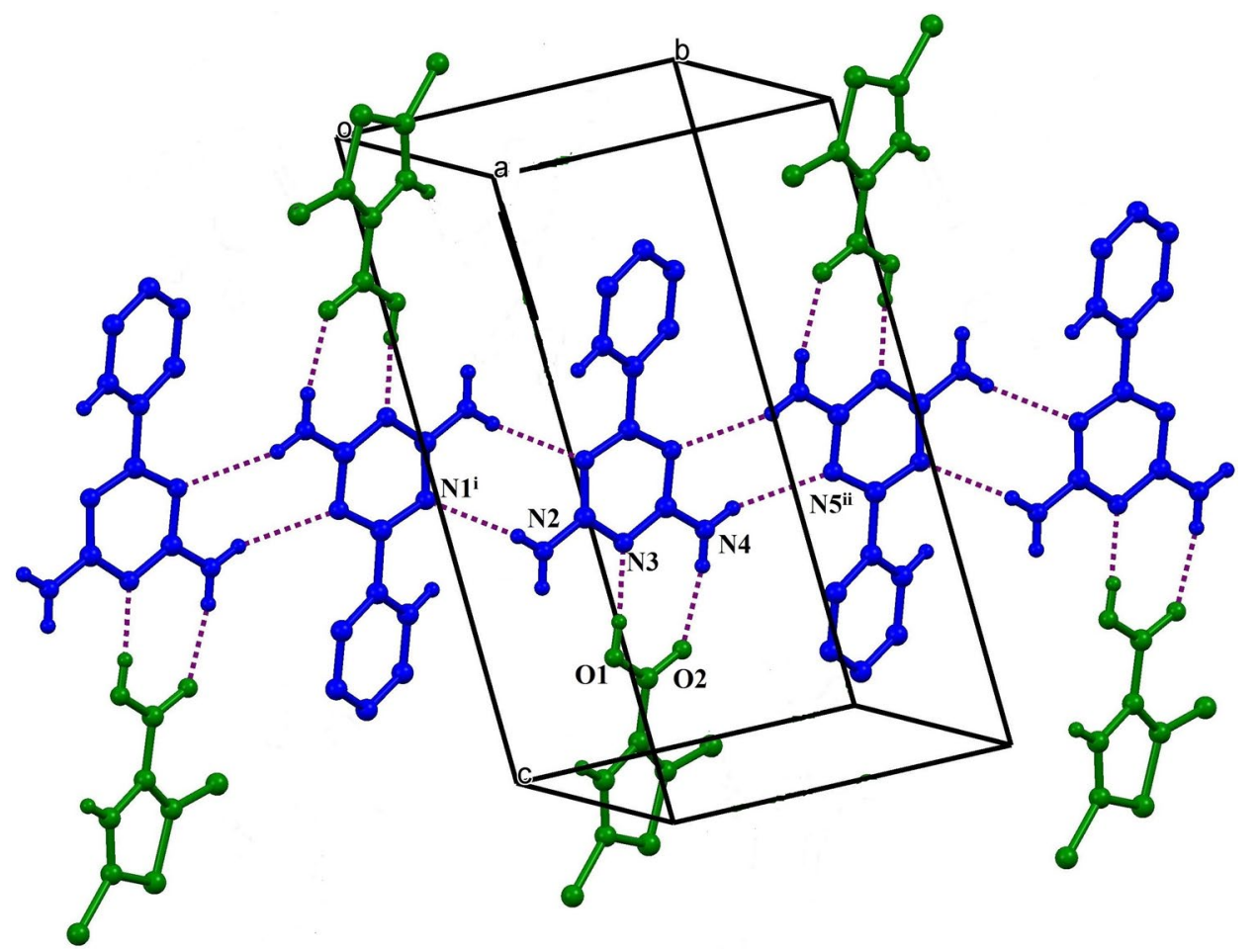

Table 4 Hydrogen-bond geometry $\left(\AA{ }^{\circ}\right)$ for (III)

\begin{tabular}{lllll}
\hline$D-\mathrm{H} \cdots A$ & $D-\mathrm{H}$ & $\mathrm{H} \cdots A$ & $D \cdots A$ & $D-\mathrm{H} \cdots A$ \\
\hline $\mathrm{O} 1-\mathrm{H} 1 \cdots \mathrm{N} 3$ & 0.82 & 1.84 & $2.6585(19)$ & 173.3 \\
$\mathrm{~N} 2-\mathrm{H} 2 \mathrm{~A} \cdots \mathrm{N} 1^{\mathrm{i}}$ & 0.86 & 2.37 & $3.185(2)$ & 157.3 \\
$\mathrm{~N}^{\mathrm{N}}-\mathrm{H} 4 \mathrm{~B} \cdots \mathrm{N} 5^{\mathrm{ii}}$ & 0.86 & 2.45 & $3.242(2)$ & 154.0 \\
$\mathrm{~N} 4-\mathrm{H} 4 \mathrm{~A} \cdots \mathrm{O} 2$ & 0.86 & 2.01 & $2.858(2)$ & 169.2 \\
$\mathrm{C} 15-\mathrm{H} 15 \cdots \mathrm{Cl}{ }^{\mathrm{iii}}$ & 0.93 & 2.77 & $3.647(2)$ & 158.5 \\
\hline
\end{tabular}

Symmetry codes: (i) $-x+1,-y,-z+1$; (ii) $-x+2,-y+1,-z+1$; (iii) $x-1, y, z$

DAPT molecules [29]. Carboxyl interaction leads to the formation of $\mathrm{R}_{2}^{2}(8)$ motif in which DCTPC molecules are appended to the ribbon of DAPT molecules (Fig. 8).

Halogen bonds have several applications in design strategies like an element for structural insulation. Recently halogen interactions are receiving wide attention and they are used in crystal engineering. Cocrystal (III) contains $\mathrm{Cl}$... O interaction (halogen bond) and $\mathrm{Cl} \ldots \mathrm{Cl}$ interactions. $\mathrm{Cl} 1 \ldots \mathrm{O} 1$ interaction at a distance of 3.1528 (18) $\AA$ with $\mathrm{C} 13-\mathrm{Cl} 1 \ldots \mathrm{O} 1$ angle of $167.96(8)^{\circ}$ (Fig. 9), shorter than the sum of the van der Waals radii $3.27 \AA[11,26]$. The Type I halogen $\cdots$ halogen $(\mathrm{Cl} 2 \ldots \mathrm{Cl} 2$ interaction at a distance of 3.4949 (11) ^) interaction [30] has also been observed (Fig. 9). Further $\pi \cdots \pi$ interactions between triazine...triazine (Cg1… $\mathrm{Cg} 1=3.6542$ (11) $\AA$, symmetry code; $2-x,-y, 1-z$ ) and triazine...phenyl rings ( $\mathrm{Cg} 1 \cdots \mathrm{Cg} 2=3.7455$ (12) $\AA$, symmetry code; $1-x, 1-y, 1-z$ ) (Fig. 10) are also observed.
Stabilization of supramolecular network by $\pi \cdots \pi$ interactions between triazine...phenyl rings among DAPT molecules with centroid to centroid distance of $3.8396(16) \AA$ is already reported [29].

Among the various non-covalent interactions present, in all the three cases we observe base pairs formed via $\mathrm{N}-\mathrm{H} \cdots \mathrm{N}$ hydrogen bonds among symmetry related molecules/ions. Literature also shows $\mathrm{N}-\mathrm{H} \cdot \cdots \mathrm{N}$ base pairs were present predominantly among self assemblies of aminotriazine derivatives [29].

\section{Conclusions}

Single crystals of two salts, 2,4-diamino-6-methyl-1,3,5triazin-1-ium 5-carboxythiophene-2-carboxylate monohydrate (I), 2,4-diamino-6-methyl-1,3,5-triazin-1-ium 3-bromothiophene-2-carboxylate monohydrate (II) and a 1:1 cocrystal, 2,4-diamine-6-phenyl-1,3,5-triazine and 2,5-dichlorothiophene-3-carboxylic acid (III) have been synthesised and characterised by single-crystal X-ray diffraction. $\mathrm{O}-\mathrm{H} \cdots \mathrm{O}, \mathrm{N}-\mathrm{H} \cdot \cdots \mathrm{O}$ and $\mathrm{N}-\mathrm{H} \cdot \cdots \mathrm{N}$ hydrogen bonding interactions are dominant in salt (I). Anion $\cdots \pi$ interactions stabilises (I) further. $\mathrm{O}-\mathrm{H} \cdots \mathrm{O}, \mathrm{N}-\mathrm{H} \cdots \mathrm{O}, \mathrm{N}-\mathrm{H} \cdots \mathrm{N}$ and $\mathrm{C}-\mathrm{H} \cdots \mathrm{O}$ hydrogen bonding interactions are dominant in salt (II). Salt (II) is further stabilised by $\pi \cdots \pi$ interactions. $\mathrm{O}-\mathrm{H} \cdots \mathrm{N}, \mathrm{N}-\mathrm{H} \cdots \mathrm{O}$ and $\mathrm{N}-\mathrm{H} \cdots \mathrm{N}$ hydrogen bonding interactions are dominant in cocrystal (III). Cocrystal (III) is further stabilised by $\mathrm{Cl} \cdots \mathrm{O}, \mathrm{Cl} \cdots \mathrm{Cl}$ as well as $\pi \cdots \pi$ interactions. 


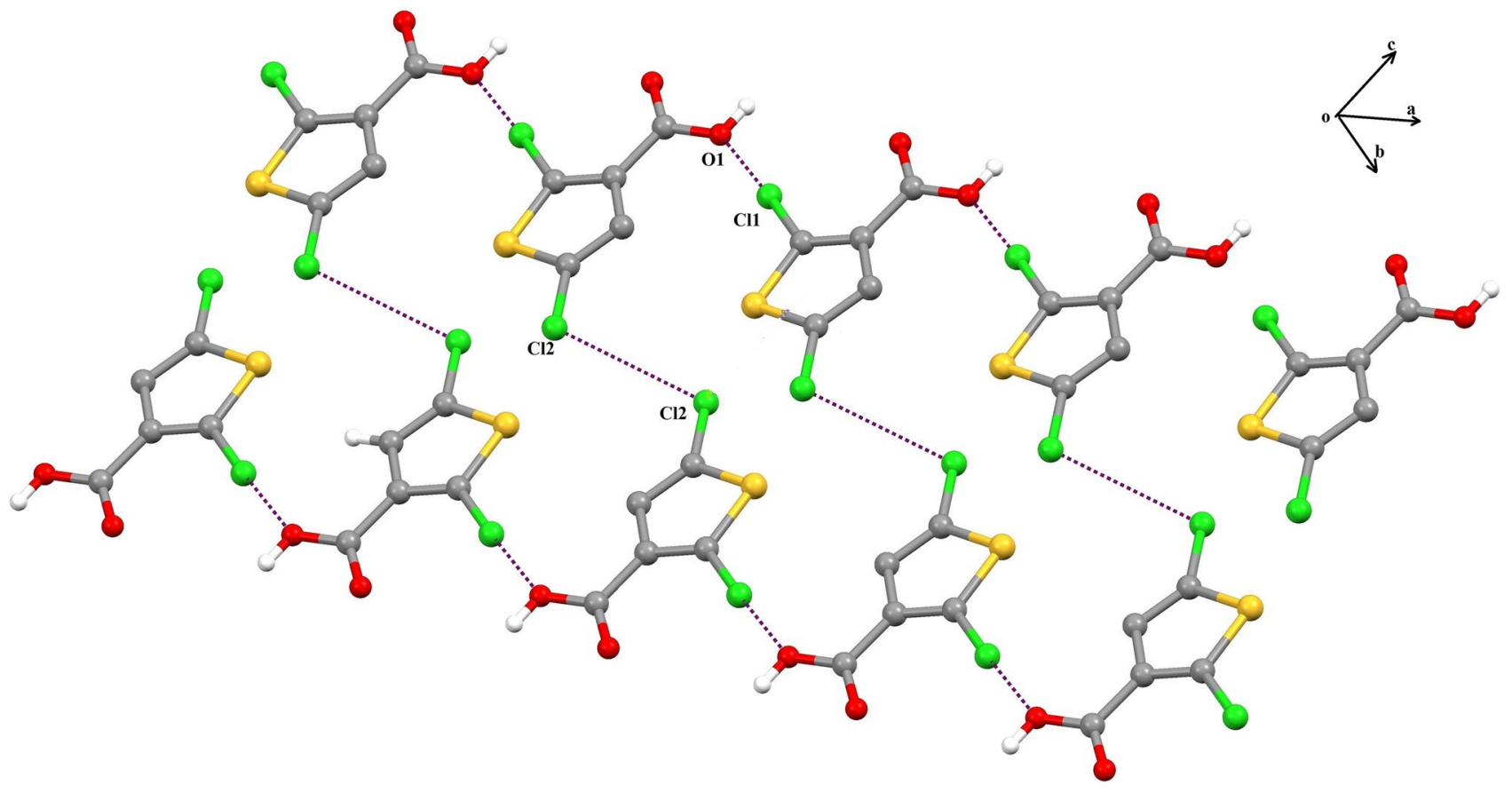

Fig. 9 Supramolecular architecture developed via $\mathrm{Cl} \ldots \mathrm{O}$ and $\mathrm{Cl} \ldots \mathrm{Cl}$ interactions in (III)

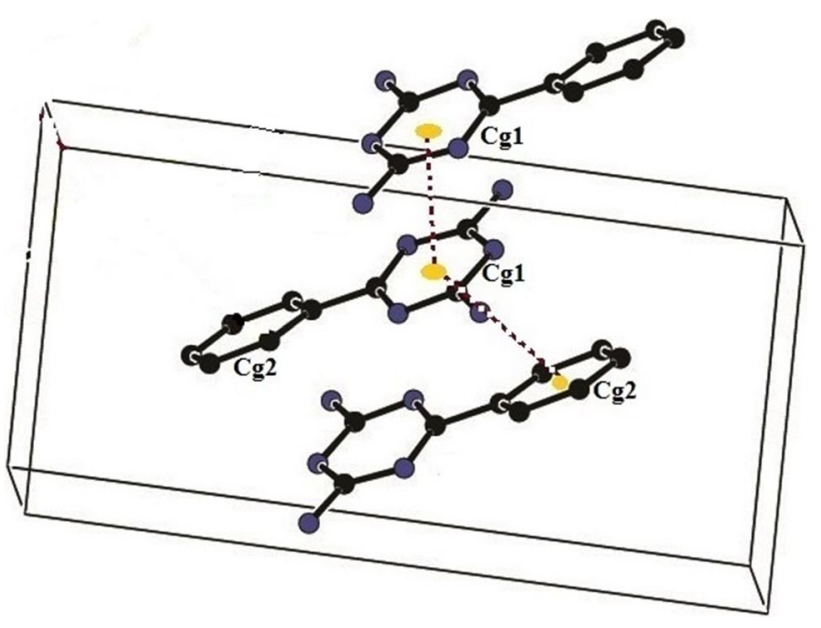

Fig. $10 \pi \cdots \pi$ interactions present in (III)

The non-covalent interactions exhibited by (I), (II) and (III) generate a variety of recurring supramolecular architectures in three-dimensional space.

Acknowledgements O. K. Prajina thanks the University Grant Commission-Special Assistance Programme and University Grant Commission-Basic Scientific Research, India for the award of Research Fellowship in Science for Meritorious Students. P. T. Muthiah thanks University Grant Commission-Emeritus Fellowship. F. Perdih thanks the EN-FIST Centre of Excellence, Ljubljana, Slovenia, for the use of the SuperNova diffractometer.

\section{Compliance with ethical standards}

Conflict of interest On behalf of all authors, the corresponding author states that there is no conflict of interest.

\section{References}

1. Lee JY, Farha OK, Roberts J, Scheidt KA, Nguyen ST, Hupp JT (2009) Metal-organic framework materials as catalysts. Chem Soc Rev 38:1450-1459. https://doi.org/10.1039/b807080f

2. Hu XP, Chen HL, Zheng Z (2005) Ferrocene-based chiral phosphine-triazines: a new family of highly efficient $P, N$ ligands for asymmetric catalysis. Adv Synth Catal 347:541-548. https://doi. org/10.1002/adsc.200404240

3. Kavalirova J, Korabik M, Stachova P, Moncol J, Sillanpaa R, Lis T, Miklos D, Melnik M, Mrozinski J, Valigura D (2008) Synthesis, spectral and magnetic properties of two different 2-nitrobenzoatocopper (II) complexes containing N, N-diethylnicotinamide. Polyhedron 27:1333-1342. https://doi.org/10.1016/j. poly.2007.12.030

4. Campbell VE, Guillot R, Riviere E, Brun PT, Wernsdorfer W, Mallah T (2013) Subcomponent self-assembly of rare-earth singlemolecule magnets. Inorg Chem 52:5194-5200. https://doi. org/10.1021/ic400098c

5. Sun M, Zhou WH, Wang YH, Tan HQ, Qi YF, Zang HY, Li YG (2016) Luminescent hybrid metal-organic coordination polymers based on $\mathrm{Cu} / \mathrm{Ag}$-bis(benzotriazole) units and polyoxometalates. J Coord Chem 69:1769-1779. https://doi.org/10.1080/00958 972.2016.1146258

6. Coppo P, Duati M, Kozhevnikov VN, Hofstraat JW, Cola LD (2005) White-light emission from an assembly comprising luminescent iridium and europium complexes. Angew Chem Int Ed Engl 44:1806-1810. https://doi.org/10.1002/anie.200461953

\section{SN Applied Sciences}


7. Kusukawa T, Fujita M (2002) Self-assembled M6L4-type coordination nanocage with 2,2'-bipyridine ancillary ligands. Facile crystallization and $\mathrm{x}$-ray analysis of shape-selective enclathration of neutral guests in the cage. J Am Chem Soc 124:1357613582. https://doi.org/10.1021/ja020712k

8. Cai W, Wang J, Chu C, Chen W, Liu G (2018) Metal-organic framework-based stimuli-responsive systems for drug delivery. Adv Sci 6:1801526-1801545. https://doi.org/10.1002/advs.20180 1526

9. Xiong S, He Y, Krishna R, Chen B, Wang Z (2013) Metal-organic framework with functional amide groups for highly selective gas separation. Cryst Growth Des 13:2670-2674. https://doi. org $/ 10.1021 / \mathrm{cg} 4004438$

10. Lu Z, Du L, Tang K, Bai J (2013) High H2 and CH4 adsorption capacity of a highly porous $(2,3,4)$-connected metal-organic framework. Cryst Growth Des 13:2252-2255. https://doi. org/10.1021/cg400449c

11. Desiraju GR (1989) In crystal engineering: the design of organic solids. Elsevier, Amsterdam

12. Gamez P, Reedijk J (2006) 1,3,5-triazine-based synthons in supramolecular chemistry. Eur J Inorg Chem. https://doi.org/10.1002/ ejic.200500672

13. Cavallo G, Metrangolo P, Milani R, Pilati T, Priimagi A, Resnati G, Terraneo G (2016) The halogen bond. Chem Rev 116:2478-2601. https://doi.org/10.1021/acs.chemrev.5b00484

14. Kowalska K, Trzybiński D, Sikorski A (2015) Influence of the halogen substituent on the formation of halogen and hydrogen bonding in co-crystals formed from acridine and benzoic acids. CrystEngComm 17:7199-7212

15. Baliani A, Bueno GJ, Stewart ML, Yardley V, Brun R, Barrett PM, Gilbert IH (2005) Design and synthesis of a series of melaminebased nitroheterocycles with activity against trypanosomatid parasites. J Med Chem 48:5570-5579. https://doi.org/10.1021/ jm050177+

16. Koc ZE, Bingol H, Saf AO, Torlak E, Coskun A (2010) Synthesis of novel tripodal-benzimidazole from 2,4,6-tris(pformylphenoxy)-1,3,5-triazine: structural, electrochemical and antimicrobial studies. J Hazard Mater 183:251-255. https://doi. org/10.1016/j.jhazmat.2010.07.018

17. Menicagli R, Samaritani S, Signore G, Vaglini F, Dalla Via L (2004) In vitro cytotoxic activities of 2-alkyl-4,6-diheteroalkyl-1,3,5triazines: new molecules in anticancer research. J Med Chem 47:4649-4652. https://doi.org/10.1021/jm0495374

18. Bojinov V, Grabchev I (2002) Synthesis and application of new combined 2,2,6,6-tetramethylpiperidine-2-hydroxybenzophenone 1,3,5-triazine derivatives as photostabilizers for polymer materials. J Photochem Photobiol A Chem 146:199-205. https ://doi.org/10.1016/S1010-6030(01)00496-8

19. Agilent (2013) CrysAlis PRO. Agilent Technologies UK Ltd, Yarnton

20. Palatinus L, Chapuis G (2007) SUPERFLIP-a computer program for the solution of crystal structures by charge flipping in arbitrary dimensions. J Appl Cryst 40:786-790. https://doi. org/10.1107/S0021889807029238

21. Sheldrick GM (2015) SHELXT - Integrated space-group and crystal-structure determination. Acta Cryst A71:3-8. https:// doi.org/10.1107/S2053273314026370

22. Spek AL (2009) Structure validation in chemical crystallography. Acta Cryst D65:148-155. https://doi.org/10.1107/S090744490 804362X

23. Macrae CF, Bruno IJ, Chisholm JA, Edgington PR, McCabe P, Pidcock E, Rodriguez Monge L, Taylor R, van de Streek J, Wood PA (2008) Mercury CSD 2.0-new features for the visualization and investigation of crystal structures. J Appl Cryst 41:466-470. https ://doi.org/10.1107/S0021889807067908

24. Zhang Q, Luo J, Ye L, Wang H, Huang B, Zhang J, Wu J, Zhang S, Tian Y (2014) Design, synthesis, linear and nonlinear photophysical properties and biological imaging application of a novel K-type pyrimidine-based thiophene derivative. J Mol Struct 1074:33-42. https://doi.org/10.1016/j.molstruc.2014.04.058

25. Allen FH, Raithby PR, Shields GP, Taylor R (1998) Probabilities of formation of bimolecular cyclic hydrogen-bonded motifs in organic crystal structures: a systematic database analysis. Chem Commun 9:1043-1044. https://doi.org/10.1039/A801424H

26. D'Ascenzo L, Auffinger P (2015) A comprehensive classification and nomenclature of carboxyl-carboxyl(ate) supramolecular motifs and related catemers: implications for biomolecular systems. Acta Cryst B71:164-175. https://doi.org/10.1107/S2052 $52061500270 \mathrm{X}$

27. Chakravarty S, Sheng Z, Iverson B, Moore B (2012) " $\eta^{6 \text { "-Type }}$ anion- $\pi$ in biomolecular recognition. FEBS Lett 586:4180-4185. https://doi.org/10.1016/j.febslet.2012.10.017

28. Portalone G, Colapietro M (2007) Hydrogen-bonded supramolecular motifs in the 1:1 monohydrated mol-ecular adduct of acetoguanaminium chloride with acetoguanamine and in 2,4,6-triamino-pyrimidine-diium dichloride dihydrate. Acta Cryst C63:0655-0658. https://doi.org/10.1107/S010827010 7046689

29. Sundaramoorthy G, Nirmalram JS, Ebenezer S, Muthiah PT (2014) Supramolecular self assemblies in polymorphs/solvates of aminopyrimidine and amino-s-triazines derivatives. J Mol Struct 1075:178-186. https://doi.org/10.1016/j.molstruc.2014.06.063

30. Lucas X, Bauza A, Frontera A, Quinonero D (2016) A thorough anion- $\pi$ interaction study in biomolecules: on the importance of cooperativity effects. Chem Sci 7:1038-1050. https://doi. org/10.1039/C5SC01386K

Publisher's Note Springer Nature remains neutral with regard to jurisdictional claims in published maps and institutional affiliations. 